\title{
Target-Derived Trophic Effect on Skeletal Muscle Innervation in Senescent Mice
}

\author{
María Laura Messi ${ }^{1}$ and Osvaldo Delbono ${ }^{1,2,3}$ \\ Departments of ${ }^{1}$ Physiology and Pharmacology and ${ }^{2}$ Internal Medicine, Gerontology and ${ }^{3}$ Neuroscience Program, Wake Forest University School of \\ Medicine, Winston-Salem, North Carolina 27157
}

In the present work, we tested the hypothesis that target-derived insulin-like growth factor-1 (IGF-1) prevents alterations in neuromuscular innervation in aging mammals. To explore this hypothesis, we studied senescent wild-type mice as a model of deficient IGF-1 secretion and signaling and S1S2 transgenic mice as a tool to investigate the role of sustained overexpression of IGF-1 in striated muscle in neuromuscular innervation. The analysis of the nerve terminal in extensor digitorum longus muscles from senescent mice showed that the decrease in the percentage of cholinesterase-stained zones (CSZ) exhibiting nerve terminal branching, number of nerve branches at the CSZ, and nerve branch points was partially or completely reversed by sustained overexpression of IGF-1 in skeletal muscle. Targetderived IGF-1 also prevented age-related decreases in the postterminal $\alpha$-bungarotoxin immunostained area, as well as the reduction in the number and length of postsynaptic folds, and area and density of postsynaptic folds studied with electron microscopy. Overexpression of IGF-1 in skeletal muscle may account for the lack of age-dependent switch in muscle fiber type composition recorded in senescent mice. In summary, the use of the S1S2 IGF-1 transgenic mouse model allowed us to provide morphological evidence for the role of target-derived IGF-1 in spinal cord motor neurons in senescent mice.

Key words: target-derived trophic effect; IGF-1; aging; neuromuscular junction; skeletal muscle; innervation; denervation; mouse

\section{Introduction}

Several groups have reported skeletal muscle denervation and reinnervation, motor unit remodeling or loss in aging rodents or humans (Hashizume et al., 1988; Kanda and Hashizume, 1989, 1992; Einsiedel and Luff, 1992; Doherty et al., 1993; Johnson et al., 1995; Zhang et al., 1996). Motor unit remodeling leads to changes in muscle fiber type composition (Pette and Staron, 2001). During development, the muscle fiber phenotype is determined by interactions with subpopulations of ventral spinal cord motor neurons that activate contraction at different rates (Buller et al., 1960a,b; Greensmith and Vrbova, 1996). Age-related remodeling of motor units appears to involve denervation of fast muscle fibers with reinnervation by axonal sprouting from slow fibers (Larsson, 1995; Lexell, 1995; Kadhiresan et al., 1996; Frey et al., 2000). When denervation outpaces reinnervation, a population of muscle fibers becomes atrophic. A recent study has shown a number of denervated fibers in old rats that accounts for a significant fraction of the decline in muscle-specific force (force normalized to muscle cross-sectional area) (Urbancheck et al., 2001).

Interventions aimed at delaying and/or preventing denervation or accelerating reinnervation will have undoubtedly a great impact on skeletal muscle maintenance and repair. Classical neurotrophic theory (Davies, 1996) describes a well established role for target-derived neurotrophic factors in the regulation of sur-

\footnotetext{
Received Aug. 29, 2002; revised 0ct. 10, 2002; accepted 0ct. 15, 2002.

This work was supported by National Institutes of Health/National Institute on Aging Grants AG18755, AG13934 and AG15820 and Muscular Dystrophy Association of America grants (0.D.)

Correspondence should be addressed to Dr. Osvaldo Delbono, Department of Physiology and Pharmacology, Wake Forest University School of Medicine, Medical Center Boulevard, Winston-Salem, NC 27157. E-mail: odelbono@wfubmc.edu.

Copyright $\odot 2003$ Society for Neuroscience $\quad 0270-6474 / 03 / 231351-09 \$ 15.00 / 0$
}

vival of developing neurons. More recent studies point to a continued role for target-derived trophic factors in the plasticity of adult and aged neurons (Cowen and Gavazzi, 1998; Bergman et al., 2000). Aging of the cutaneous innervation, manifested in degenerative and regenerative events, seems strongly associated with changes in neurotrophic interactions between sensory neurons and target tissues (Bergman et al., 2000).

One of the muscle factors that appear to be vital for the protection of nerve and muscle from age-related degeneration is insulin-like growth factor-1 (IGF-1). The role of IGF-1 in motor neuron survival has been examined during embryonic or early postnatal life (Neff et al., 1993), as well as in spinal cord pathology (Rind and von Bartheld, 2002). For example, in young rodents, IGF-1 expression is upregulated in Schwann cells and astrocytes after spinal cord and peripheral nerve injury, whereas IGFbinding protein- 6 is strongly upregulated in the injured motor neurons (Hammarberg et al., 1998). In young animals, systemic administration of IGF-1 decreases lesion-induced motor neuron cell death and promotes muscle reinnervation (Vergani et al., 1998). Despite a large body of evidence supporting IGF-1 as a promoter of neurogenesis and synaptogenesis in diverse areas of the CNS during the perinatal period (Ye et al., 1996; O'Kusky et al., 2000), a key question remains to be answered: are the beneficial effects of IGF-1 on neurons retained in adult and aged organisms? Answers to this question are not currently available. The involvement of IGF-1 in the neuronal aging process remains substantially untested and is the main goal of the present study.

\section{Materials and Methods}

Animals and muscle dissection. Young-adult (2-6 months) or old (22-24 months) FVB or S1S2 IGF-1 transgenic mice (Coleman et al., 1995; Renganathan et al., 1997b, 1998) were used in the present study. Briefly, S1S2 mice were generated using the FVB as the background strain. The avian 
skeletal $\alpha$-actin gene was used as a template for construction of a myogenic expression vector that was used to direct expression of a human IGF-1 cDNA in striated skeletal muscle of transgenic mice (S1S2). Previous studies from our and other laboratories have shown overexpression of IGF-1 in skeletal muscles from young-adult and senescent S1S2 mice (Coleman et al., 1995; Renganathan et al., 1998). No IGF-1 overexpression was detected in other peripheral organs, CNS (Coleman et al., 1995), or plasma (Coleman et al., 1995; Delaughter et al., 1999). The FVB and S1S2 strains have been used previously as animal models of aging (Bakker et al., 1997; Renganathan et al., 1997b, 1998; Zheng et al., 2001a). Mice were housed in a pathogen-free area at Wake Forest University School of Medicine (WFUSM). Animal handling and procedures followed an approved protocol by the Animal Care and Use Committee of WFUSM. Mice were killed by cervical dislocation, and the extensor digitorum longus (EDL) muscles were dissected.

Skeletal muscle fiber typing. Skeletal muscle fiber typing was done by immunohistochemistry following published procedures (Ecob-Prince et al., 1989; Hughes et al., 1993; Schiaffino and Reggiani, 1994), with some modifications. Briefly, EDL muscles were pinned to the bottom of embedding molds, covered with OCT medium (Tissue-Tek, Torrance, CA), and rapidly frozen in 2-methylbutane (Fisher Scientific, Pittsburgh, PA) cooled in dry ice at $-40^{\circ} \mathrm{C}$. Muscles were stored at $-80^{\circ} \mathrm{C}$ for subsequent use. Frozen samples were sectioned with a cryostat (model CM3000; Leica, Nussloch, Germany) at $-21^{\circ} \mathrm{C}$. Sections, of $10 \mu \mathrm{m}$ thickness, were stored at $4^{\circ} \mathrm{C}$ until processed. For muscle fiber subtype identification, muscle sections were exposed to the primary antibody NCL-MHCs (type-I), NCL-MHCf (total fast) (Novocastra, Newcastle upon Tyne, UK), A4.74 (type IIA) (Alexis Biochemicals, San Diego, CA), or BF-F3 (type IIB) (American Type Culture Collection, Rockville, MD) at 1:20 dilution in PBS. A rabbit anti-mouse IgG FITC conjugate (Sigma, St. Louis, MI) was used as a secondary antibody at a 1:100 dilution. The number of fibers expressing MHC IIX was obtained by subtracting IIA and IIB fibers to the total number of fast fibers detected with the NCLMHCf antibody. Muscle fluorescence immunostaining was analyzed using an inverted microscope (Axiovert 100; Zeiss, Oberkochen, Germany) and a PXL-EEV-37 CCD camera (Photometrics, Tucson, AZ) based imaging system. Isee software (Inovision, Durham, NC) running in a Silicon Graphics (Mountain View, CA) O2 workstation was used for data acquisition and image processing.

Myosin heavy chain isoforms composition in EDL muscles. Myosin heavy chain (MHC) composition of EDL muscles was determined by SDSPAGE, as described previously (Serrano et al., 1996) with some modifications. Briefly, EDL muscles were minced on ice in $4 \mathrm{vol}$ of a high salt buffer (in mm: $300 \mathrm{NaCl}, 100 \mathrm{NaH}_{2} \mathrm{PO}_{4}, 50 \mathrm{Na}_{2} \mathrm{HPO}_{4}, 1 \mathrm{MgCl}_{2}, 10$ $\mathrm{Na}_{4} \mathrm{P}_{2} \mathrm{O}_{7}$, and 10 EDTA, pH 6.5). Extracts were then centrifuged at $13,000 \mathrm{rpm}$ for $30 \mathrm{~min}$ at $2^{\circ} \mathrm{C}$ in a microcentrifuge. The supernatants were diluted in 9 vol of $1 \mathrm{~mm}$ EDTA buffer [37\% (w/v) EDTA and $0.01 \%$ (v/v) 20-mercaptoethanol], vortexed, and allowed to precipitate overnight at $4^{\circ} \mathrm{C}$. Centrifugation was repeated, and the resulting pellet dissolved in $0.5 \mathrm{M} \mathrm{NaCl}$ and $10 \mathrm{mM} \mathrm{NaPO}_{4}$ and denatured by immersion in boiling water for at least $2 \mathrm{~min}$. Samples were diluted 1:100 in SDS buffer [62.5 mm Tris- $\mathrm{HCl}, 2 \%(\mathrm{w} / \mathrm{v})$ SDS, $10 \%$ (v/v) glycerol, and $0.001 \%(\mathrm{w} / \mathrm{v})$ bromophenol blue, $\mathrm{pH}$ 6.8]. Electrophoresis was performed in $6 \%$ acrylamide (40\%, 37.5:1; Bio-Rad, Hercules, CA) separating gel with $30 \%$ $(\mathrm{v} / \mathrm{v})$ glycerol and $3 \%$ stacking gel with no glycerol. Ten microliters aliquots of diluted myosin were subject to electrophoresis for $6 \mathrm{hr}$ at $50 \mathrm{~V}$ and $12 \mathrm{hr}$ at $120 \mathrm{~V}$ at $4^{\circ} \mathrm{C}$. Gels were silver stained according to published protocols (Giulian et al., 1983) using the silver stain plus kit and Silver Stain SDS-PAGE Standards, high range (Bio-Rad). Diaphragms from young-adult mice were used as a reference for the four MHC isoforms (I, IIA, IIB, and IIX).

Cholinesterase-staining procedure. A combined stain for the demonstration of motor nerve terminals and cholinesterase at the neuromuscular junctions (NMJs) was used (Pestronk and Drachman, 1978) with some modifications. This procedure used bromoindoxyl acetate dye staining for cholinesterase and silver-gold impregnation for nerve terminals. EDL muscles were pinned to the bottom of embedding molds at resting length, covered with OCT, and quickly frozen by immersion in isopentane cooled with dry ice. Longitudinal sections (30 $\mu \mathrm{m}$ thick) were cut with a cryostat. Sections were placed on a slide in a drop of $3 \%$ disodium EDTA (which is used to prevent contracture of muscle fibers) and air dried at $37^{\circ} \mathrm{C}$. For the cholinesterase-staining procedure, the slides were immersed in a $20 \%$ solution of sodium sulfate to prevent shrinkage of sections in the cholinesterase stain. Sections were incubated for $8-10 \mathrm{~min}$ in the staining solution described previously (Pestronk and Drachman, 1978). For the nerve-staining procedure, the sections were dehydrated to prevent loss from slides and treated subsequently as described previously (Pestronk and Drachman, 1978).

Immunocytochemical analysis. For postsynaptic acetylcholine receptor staining, longitudinal cryosections $(30 \mu \mathrm{m})$ of EDL muscles were fixed in methanol/acetone $(50: 50 \mathrm{v} / \mathrm{v})$ for $10 \mathrm{~min}$ at room temperature. After washing in Tris-buffered saline (TBS), the sections were blocked in TBS containing $10 \%$ normal rabbit serum for $30 \mathrm{~min}$ and washed out in TBS. Sections were incubated with tetramethylrhodamine-conjugated $\alpha$-bungarotoxin antibody (Molecular Probes, Eugene, OR), diluted at 1:200 in the TBS, for $3 \mathrm{hr}$. Immunostained junctions were visualized using a Zeiss Axiovert microscope equipped with a CCD-EEV37 camera. Images were analyzed using Isee software (Inovision) (see above). The postterminal area was calculated by tracing the perimeter of individual immunolabeled regions on digitized images. The enclosed area was measured in pixels and converted into square micrometers.

Electron microscopy. EDL muscles were fixed in vitro in $0.5 \%$ gluteraldehyde-4\% paraformaldehyde in PBS for 30-60 min. Tissue was rinsed in PBS, and the bands of neuromuscular junctions were visualized using Karnovsky's method (Karnovsky and Roots, 1964). The endplate band was then cut out and processed for electron microscopy according to standard procedures (Jerome et al., 1991).

Statistics. Values are given as mean \pm SEM with the number of observations $(n)$. Statistical analysis has been performed using ANOVA or Student's unpaired $t$ test and Mann-Whitney rank sum test when values were not normally distributed. $p<0.05$ was considered significant.

\section{Results}

\section{Changes in muscle fiber type composition with age and} transgenic overexpression of IGF-1 in skeletal muscle

The analysis of the fiber type composition of the mouse fasttwitch skeletal muscle EDL by immunohistochemistry shows three fiber subtypes: I, IIA, and IIB. The predominant MHC isoform was IIB, followed by IIA and I, as shown in Figure 1. The expression of MHC IIX/D was not detected in any of the four groups of EDL muscles studied regardless of age or genotype. Fiber subtypes were expressed as a percentage of the total number of fibers counted for individual muscles. The total number of fibers did not differ significantly among different age groups, wild type, and IGF-1 transgenic. The total number of fibers was as follows (mean $\pm \mathrm{SEM} ; n=7$ EDL muscles from six mice per group): $646 \pm 39,647 \pm 52,598 \pm 51$, and $564 \pm 32$, for young, young transgenic, old, and old transgenic mice, respectively $(p>$ 0.05 ). The number of type IIB fibers decreased significantly in old wild-type compared with young wild-type and young transgenic mice $(p<0.05)$. This phenomenon was associated with an increase in type IIA fibers $(p<0.05)$. Although an increase in type I fibers seems to be apparent in old wild-type compared with young wild-type and transgenic mice, this difference was not statistically significant.

Overexpression of IGF-1 in skeletal muscle prevented the agedependent decrease in type IIB and the increase in type IIA fibers reported above. The percentage of fibers expressing type IIB and A MHC isoforms in old transgenic did not differ significantly from that reported in young wild-type and transgenic mice. Changes in type IIB and IIA fibers in old transgenic compared with old wild-type mice were significantly different $(p<0.05)$. These results support previous observations on the role of IGF-1 in preserving and/or delaying skeletal muscle fiber type composition in aging rodents by preventing the switching in type IIB to 


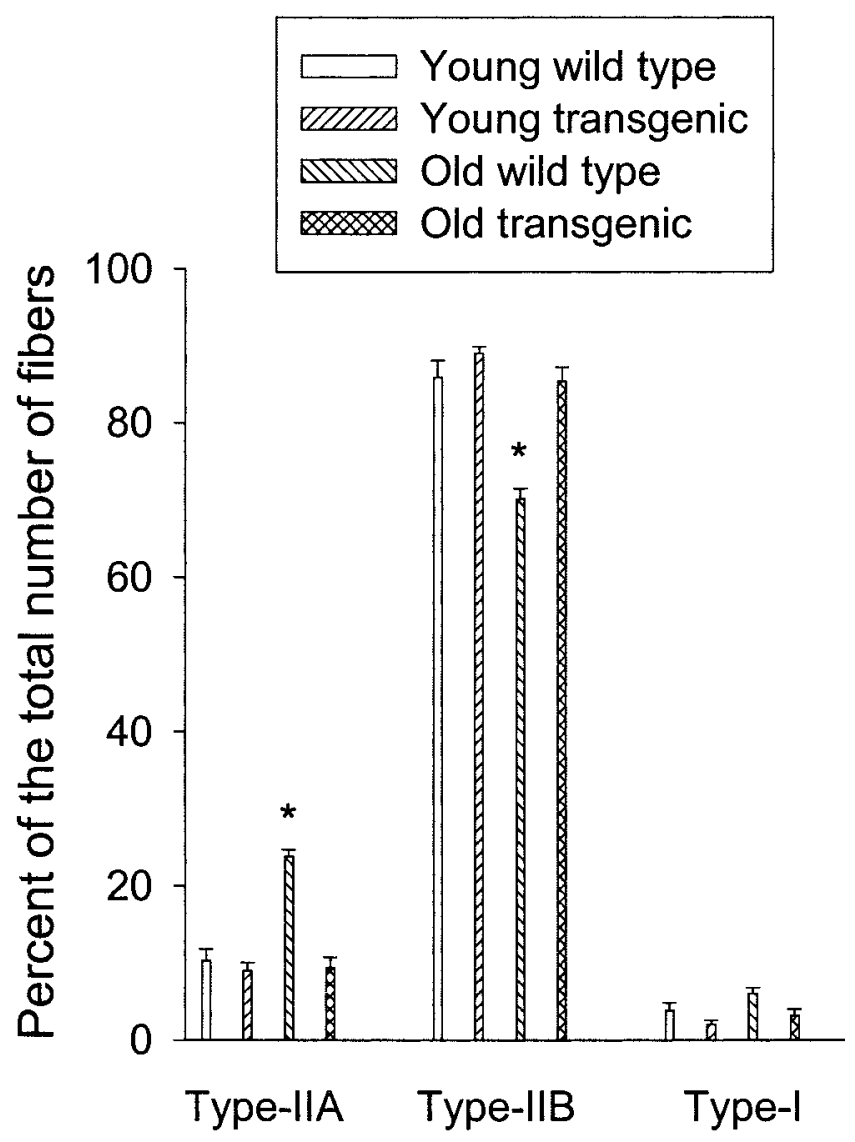

Figure 1. Fiber type composition of the mouse EDL muscle from young and old wild-type and IGF-1 transgenic mice. Fiber subtypes have been analyzed by immunohistochemistry using monoclonal antibodies against specific MHC isoforms (see Materials and Methods). Results are expressed as (mean \pm SEM) a percentage of the total number of fibers. Asterisks indicate statistically significant difference with young wild-type and transgenic (young and old) mice $(p<0.05)$.

slower fiber subtypes (see Discussion). The lack of significant changes in the total number of fibers in EDL muscles from mice of different ages, as described above, support the conclusion that changes in fiber type composition in old compared with young wild-type mice is explained by fiber type switching and not by a net loss of muscle fibers. This switch in fiber type composition has been attributed to a denervation-reinnervation process leading to motor unit remodeling in senescent rodents (for review, see Larsson, 1995).

To confirm the observation on the age-dependent switch in fiber type composition and the absence type IIX fibers in EDL muscle with a different methodology, we used SDS-PAGE gels as described previously (Giulian et al., 1983; González et al., 2000). The gel depicted in Figure 2 shows four bands in the standard corresponding to MHC IIA (slowest), IIX, IIB, and I (fastest) isoforms. We used mouse diaphragm as a standard $(S t)$ for these experiments on the basis of the expression of the four MHC isoforms. None of the four samples corresponding to young $(Y)$, young transgenic $(Y T)$, old $(O)$, and old transgenic (OT), exhibited MHC IIX, in agreement with the experiments, described above, on muscle immunostaining. It is also apparent that the increase in type IIA as well as the decrease in IIB MHC with aging is more marked in old wild-type than in old transgenic mice. These experiments were repeated thrice, showing the same MHC pattern.

To determine whether local overexpression of IGF-1 pre-

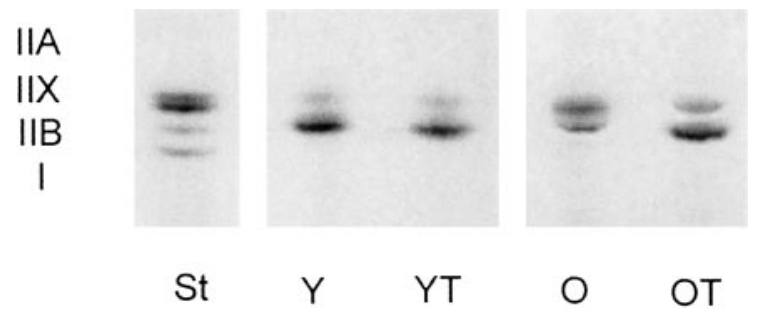

Figure 2. Myosin heavy chain isoforms detected by SDS-PAGE gel analysis. MHC isoforms (types IIA, IIX, IIB, and I) in EDL muscles from young wild-type ( $Y$, young IGF-1 transgenic (YT), old wild-type ( 0 ), and old transgenic (OT) mice. The first lane on the left corresponds to mouse diaphragm used as the standard (St) exhibiting the four MHC isoforms.

vents-delays denervation-reinnervation by acting exclusively on the target (skeletal muscle), muscle innervation, or both, we studied the nerve terminals and neuromuscular junction of the animals exhibiting the described changes in muscle fiber type composition.

\section{NMJ in aging and IGF-1 transgenic mice}

We used a combined silver-cholinesterase staining method to visualize NMJs in longitudinal cryosections of EDL muscles from young-adult and senescent mice. This technique displays the cholinesterase-containing endplate as a well demarcated transparent blue zone, against which the black silver-stained nerve terminals stand out clearly (Pestronk et al., 1980). Twenty endplates from each muscle from four animals were measured for each group (young and old, wild-type and IGF-1 transgenic mice). The following six parameters were quantified: (1) percentage of cholinesterase-stained zones (CSZ) exhibiting nerve terminal branching, (2) number of nerve branches at the CSZ, (3) number of nerve terminal branch points within the CSZ, (4) percentage of nerve terminals exhibiting sprouting outside the CSZ, (5) nerve thickness measured outside the CSZ, and (6) endplate area as outlined by the cholinesterase stain.

Fig. 3 illustrates NMJs corresponding to EDL muscles from young wild-type $(A)$, young transgenic $(B)$, old wild-type $(C)$, and old transgenic $(D)$ mice. Figure $3 A$ shows that the nerve terminals have multiple branches within the CSZ in the NMJ from young mice, a pattern that was observed in $100 \%$ of the terminals studied ( $n=86$ from four EDL muscles of four mice) (Fig. 4A). This pattern was also observed in $100 \%$ of the NMJ analyzed in young transgenic mice ( $n=90$ from four EDL muscles of four mice) (Fig. $3 B$ ). A reduction in the number of nerve terminals is apparent in old wild-type mice (Fig. $3 C$ ) in which $86 \%$ of the NMJ exhibited nerve branching ( $n=88$ from four EDL muscles of four mice) (Fig. 4A). This was associated with a significant reduction in the number of branches (Fig. $4 B$ ), as well as in the number of nerve branch points (Fig. $4 C$ ) in old wild-type compared with young wild-type and transgenic mice $(p<0.05)$. A pattern similar to that described for young wild type and transgenic was observed in old transgenic mice transgenic $(n=94$ from four EDL muscles of four mice) (Fig. 3D), in which $96 \%$ of the NMJs exhibited nerve terminal branching within the CSZ (Fig. 4A). The difference between old transgenic and old wild type was statistically significant $(p<0.05)$, whereas the difference between old transgenic and young groups wild type and transgenic, was not significant.

The number of extraterminal sprouts, nerve thickness, and CSZ area differed among animals of different age and genotype. Extraterminal sprouts were only seen in $7 \%$ of the NMJs studied in young wild-type mice, whereas this number increased in old 

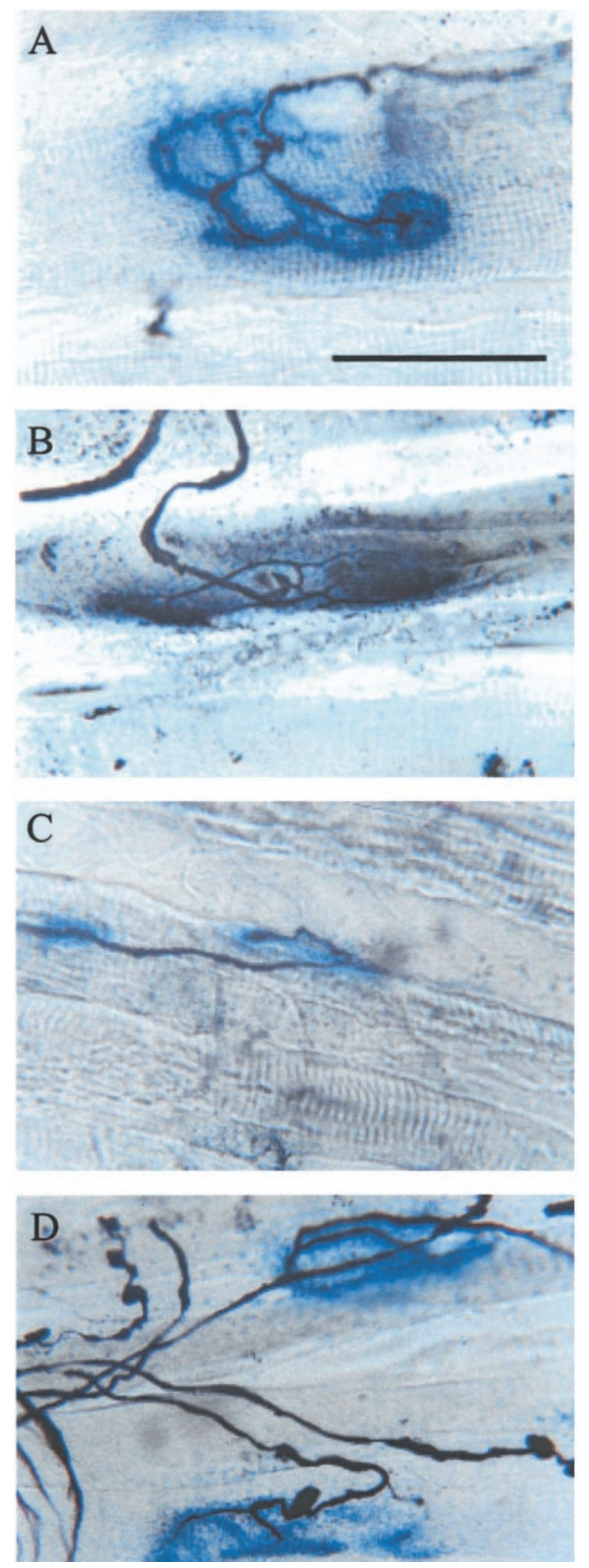

Figure 3. NMJ in aging and IGF-1 transgenic mice. Combined silver-cholinesterase staining of longitudinal cryosections of EDL muscles from young $(A)$, young transgenic $(B)$, old $(C)$, and old transgenic (D) mice. The cholinesterase stained zone is in blue. Scale bar, $50 \mu \mathrm{m}$.

wild type to $12 \%$. A more significant increase was recorded in transgenic young (24\%) and old (31\%) mice (Figs. 3, 4D). It is obvious that transgenic overexpression of IGF-1 in skeletal muscle resulted in several-fold increase in nerve sprouting in both
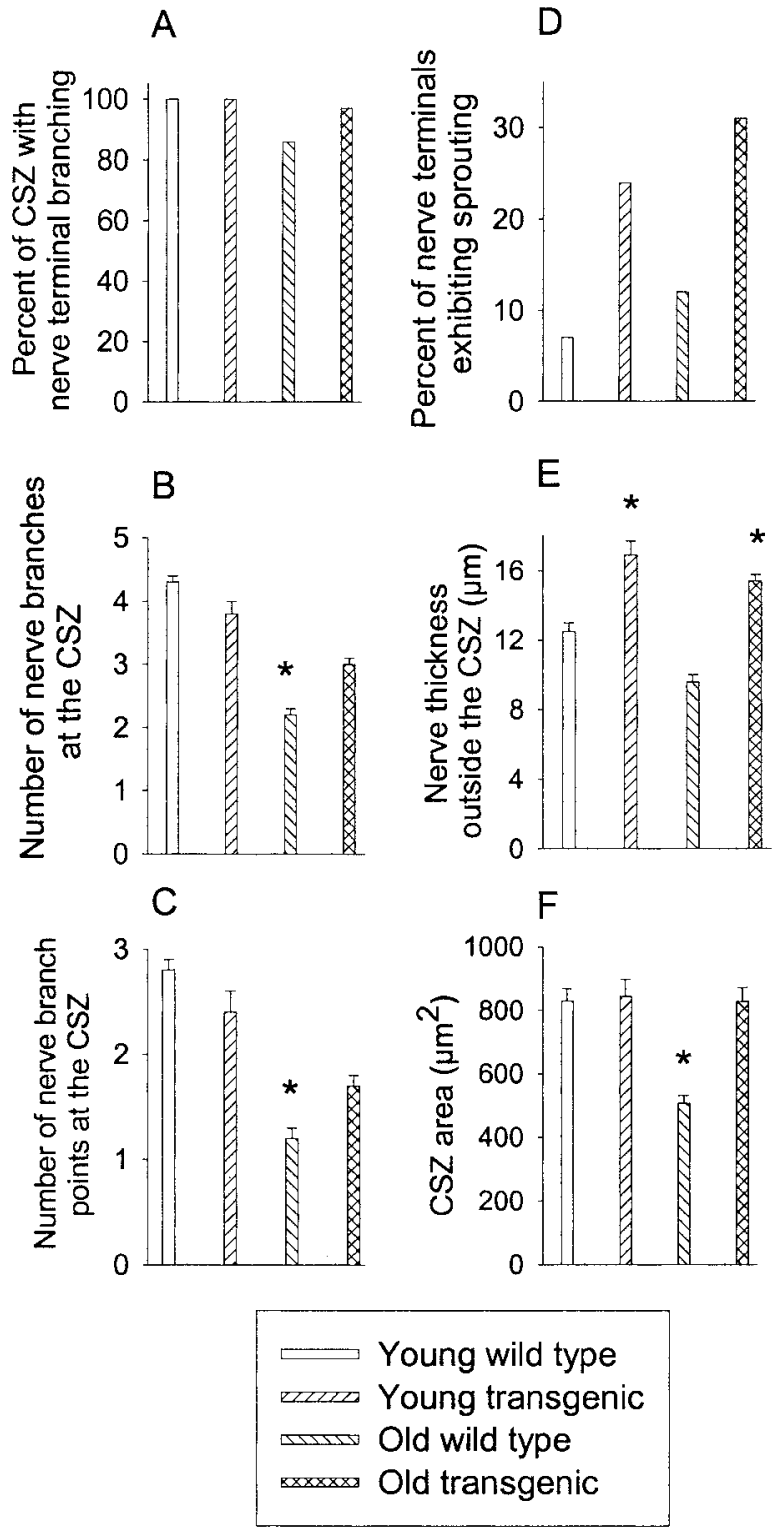

Figure 4. Analysis of the neuromuscular junction using the combined silver-cholinesterase staining. Presynapse and nerve terminal outside and within the CSZ in EDL muscle from young and old wild-type and IGF-1 transgenic mice. Results are represented as mean and SEM, except for $A$ and $D$, which are expressed as mean values. Asterisks indicate statistically significant difference ( $p<0.05$ ), in $B, C$, and $F$ with the other three groups (young wild type and transgenic and old transgenic), and in $E$ between transgenic and wild-type groups.

young and old mice. Figures 3 and $4 E$ show that nerve terminals become thinner with senescent and that muscle overexpression of IGF- 1 results in a marked increase in nerve thickness in both young and old mice. Figures 3 and $4 F$ also show that the area of the presynaptic terminal was significantly reduced with aging, a phenomenon that was prevented by overexpression of IGF-1 in skeletal muscle.

\section{Analysis of the NMJ postterminal}

Postsynaptic acetylcholine receptors were stained with rhodamine-conjugated $\alpha$-bungarotoxin. The area of the postterminal measured with this method is an indication of the complexity of the sarcolemmal infoldings and number and distribution of acetylcholine receptors. For the calculation of this area, the perimeter of the postterminal was traced, and the enclosed surface was 


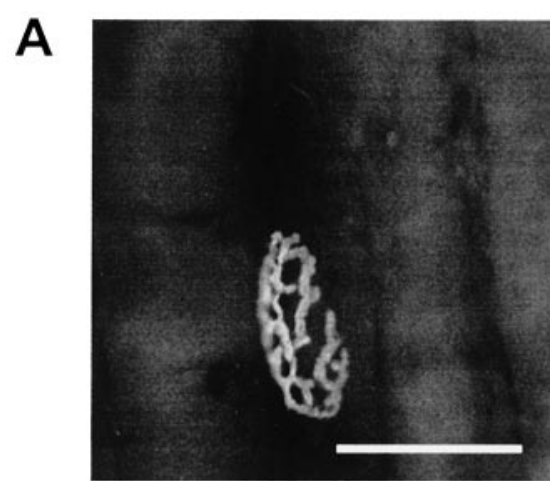

B
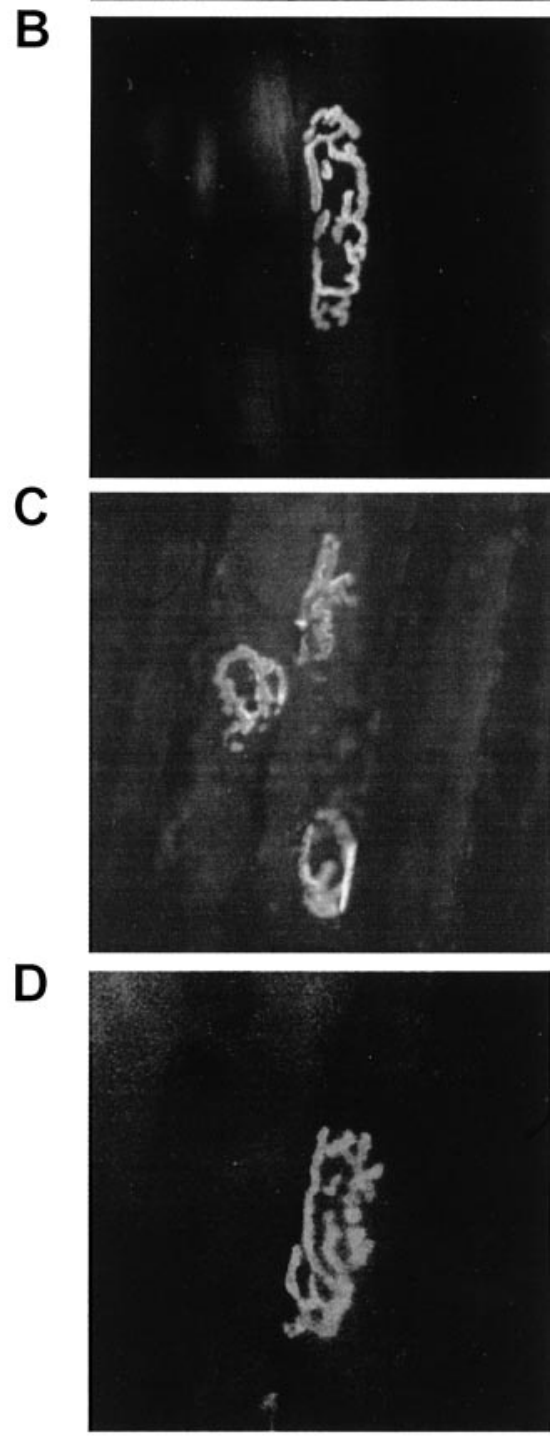

Figure 5. Analysis of the neuromuscular junction postterminal. Postsynaptic acetylcholine receptors in longitudinal sections of EDL muscles from young $(A)$ and old $(B)$ wild-type, and young $(C)$ and old $(D)$ IGF-1 transgenic mice were stained with rhodamine-conjugated $\alpha$-bungarotoxin. Scale bar, $30 \mu \mathrm{m}$.

calculated using digitized images (see Materials and Methods). A total of 20-25 NMJs were analyzed from at least three muscles from different mice for each group (young and old wild type and transgenic). Figure 5 shows that the simplification, shrinkage, and fragmentation of the postterminal in EDL muscles from old $(B)$ compared with young $(A)$ mice was the most striking observation. No obvious difference in postterminal size and complex-

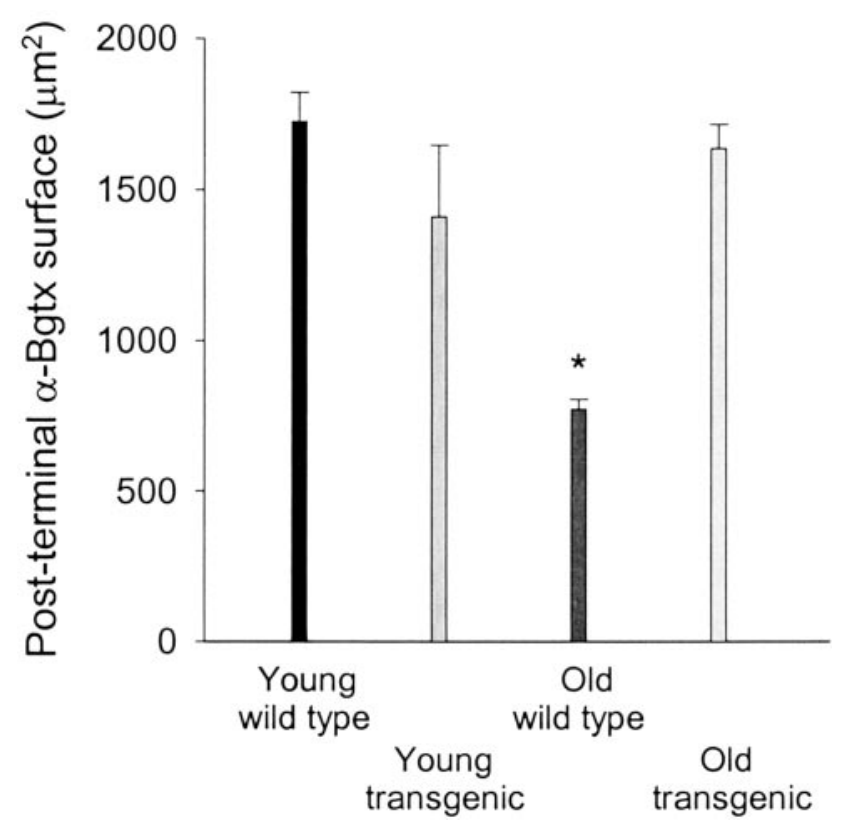

Figure 6. Postterminal area. The NMJ postterminal area was analyzed by immunostaining acetylcholine receptors with fluorescent-labeled $\alpha$-bungarotoxin. Asterisk indicates statistically significant difference with the other three groups $(p<0.05)$. Values are expressed as mean \pm SEM.

ity was found between young wild-type and young transgenic $(C)$ or old transgenic $(D)$ mice. Measurements of the postterminal area delimited by fluorescent $\alpha$-bungarotoxin showed a marked decrease in old wild-type mice compared with young wild-type and transgenic mice $(p<0.05)$ (Fig. 6). This age-dependent phenomenon was precluded by chronic overexpression of IGF-1 in skeletal muscle $(p<0.05)$.

\section{Electron microscopy of the postterminal junction}

The analysis of the NMJ with electron microscopy was performed in $15,18,17$, and 20 endplates from at least three EDL muscles from young, young transgenic, old, and old transgenic mice, respectively. A significant decrease in the number of postsynaptic folds in EDL muscles from old compared with young wild-type mice was observed (Fig. 7A, B; Table 1). These results are compatible with the simplification of the postterminal described for rhodamine-labeled $\alpha$-bungarotoxin experiments (see above). The analysis of the number of postsynaptic folds in EDL muscles from young and old transgenic did not show significant differences with young transgenic mice (Fig. 7C,D; Table 1). The length of the postsynaptic folds was measured by tracing the contour of individual sarcolemmal folds using a digital image processing software (see Materials and Methods). The length of the infoldings, measured in pixels, was transformed into micrometers by using a calibration standard. Similarly, the total length of the postsynapse was measured as the length of the total number of postsynaptic folds. Both parameters were significantly reduced in old wild type compared with the other three groups (Table 1). The area of the postsynapse, measured as the surface of the total number of postterminal folds per nerve terminal, and the density of postsynaptic folds, calculated as the ratio between the total length of postsynaptic folds and the postsynapse area (Fahim and Robbins, 1982), were also significantly reduced in EDL muscles from old wild-type compared with old transgenic and young wild-type and transgenic mice (Table 1). On the basis of these 
results, we conclude that transgenic overexpression of IGF-1 in skeletal muscle prevents age-dependent ultrastructural changes of the NMJ postterminal.

\section{Discussion}

In the present study, we tested the hypothesis that target-derived IGF-1 prevents alterations in neuromuscular innervation in aging mammals. To explore this hypothesis, we studied senescent wild-type mice as a model of decline in muscle IGF-1 concentration and signaling (Renganathan et al., 1997a, 1998; Delbono, 2000; Owino et al., 2001) and S1S2 transgenic mice as a tool to investigate the role of sustained overexpression of IGF-1 in striated muscle (Coleman et al., 1995; Renganathan et al., 1998; Zheng et al., 2001b) in neuromuscular innervation. The main conclusion of the present study is that muscle IGF-1 prevents agedependent changes in nerve terminal and neuromuscular junction, having an impact on muscle fiber type composition and potentially on muscle function (Barton-Davis et al., 1998; Musaro et al., 2001; Delbono, 2003).

Skeletal muscle fiber type composition Denervation leads to a series of changes in skeletal muscles from rodents, such as reorientation of costameres (rib-like structures formed by dystrophin and $\beta$ dystroglycan) (Bezakova and Lomo, 2001), proliferation of triadic membranes (Salvatori et al., 1988), decrease in the functional expression of the dihydropyridine receptor voltage sensor, and alterations in the sarcoplasmic reticulum calcium release channel (Delbono, 1992; Delbono and Stefani, 1993; Delbono and Chu, 1995; Damiani et al., 1996). Some of these changes have been described in aging muscle (Delbono et al., 1997; Wang et al., 2000). EDL muscles from aging wild-type mice exhibit a switch in fiber type composition, a phenomenon that is prevented by overexpression of IGF-lin skeletal muscle. This finding is in agreement with a previous report in rat (Barton-Davis et al., 1998). Whether the predominant loss of some type IIB fibers in rodents results from age-related muscle denervation, greater susceptibility to direct fiber injury, reduced motor neuron activity, or decrease in motor neuron expression and/or response to IGF-1 is not known. Age-related remodeling of motor units appears to involve denervation of fast muscle fibers with reinnervation by axonal sprouting from slow fibers (Larsson, 1995; Lexell, 1995; Kadhiresan et al., 1996; Frey et al., 2000).

The preventive effect of muscle IGF-1 on the age-dependent decrease in type IIB fibers (Barton-Davis et al., 1998; Musaro et al., 2001) suggests that, in addition to an autocrine-paracrine effect, IGF-1 plays a role in the control of muscle fiber composition by acting on the motor neuron.

\section{IGF-1 and muscle innervation in senescent mice}

The age-dependent changes in nerve terminal and NMJ preterminal reported here are consistent with previous reports (Rob- bins and Nakashiro, 1993). The decrease in the percentage of CSZ exhibiting nerve terminal branching, number of nerve branches at the CSZ, and nerve branch points with aging was partially or completely reversed by overexpressing IGF-1 in skeletal muscle. Although the number of nerve branches and nerve branch points at the CSZ in transgenic senescent were not normalized to the level observed in young mice, the values were significantly different from those recorded in old wild-type mice. The changes in these parameters together with those observed in the percentage

Table 1. Ultrastructural analysis of the neuromuscular junctions in the EDL muscle of transgenic and wild-type mice

\begin{tabular}{clllll}
\hline & $\begin{array}{l}\text { Number of } \\
\text { postsynaptic } \\
\text { folds }\end{array}$ & $\begin{array}{l}\text { Length of } \\
\text { postsynaptic } \\
\text { folds }(\mu \mathrm{m})\end{array}$ & $\begin{array}{l}\text { Total length of } \\
\text { postsynapses } \\
(\mu \mathrm{m})\end{array}$ & $\begin{array}{l}\text { Area of the } \\
\text { postsynapses } \\
\left(\mu \mathrm{m}^{2}\right)\end{array}$ & $\begin{array}{l}\text { Density of } \\
\text { postsynaptic } \\
\text { folds }\left(\mu \mathrm{m} / \mu \mathrm{m}^{2}\right)\end{array}$ \\
\hline $\begin{array}{c}\text { Young wild type } \\
(n=15)\end{array}$ & $16.7 \pm 1.1$ & $0.79 \pm 0.05$ & $25 \pm 1.1$ & $4.3 \pm 0.8$ & $6.9 \pm 1.3$ \\
$\begin{array}{c}\text { Young transgenic } \\
(n=17)\end{array}$ & $17.5 \pm 0.5$ & $0.65 \pm 0.04$ & $27 \pm 3.0$ & $4.4 \pm 1.4$ & $6.6 \pm 1.4$ \\
$\begin{array}{c}\text { Old wild type } \\
(n=18)\end{array}$ & $13.5 \pm 1.4^{*}$ & $0.47 \pm 0.02^{*}$ & $20 \pm 0.5^{*}$ & $2.9 \pm 0.6^{*}$ & $5.1 \pm 0.8^{*}$ \\
Old transgenic \\
$(n=20)$
\end{tabular}

Values are mean \pm SEM. *Indicates statistically significant difference with young wild-type, young transgenic, and old transgenic mice. The density of the postsynaptic folds was calculated as the ratio between the total length and the area of the postsynapses. 
of CSZ with nerve terminal branching in senescent transgenic mice may impact the population of muscle fibers.

The percentage of nerve terminals exhibiting sprouting increased with aging in agreement with previous reports in which an increase in the complexity of the nerve terminal has been reported (Robbins, 1992). This finding was more obvious in transgenic than in their age-matched wild-type mice. A significant reduction in nerve sprouting in adult rats treated with neutralizing antibodies to IGF-1 has been described previously (Streppel et al., 2002). IGF-1 also promotes neurite growth in cultured adult sensory neurons (Kimpinski and Mearow, 2001). On this basis, it appears that IGF-1 induces nerve sprouting. In this study, we also report that nerve terminal thickness, which was significantly reduced in old wild type, is increased in young and old transgenic mice. These results are in agreement with studies in which IGF-I deficiency is associated with decreased axonal diameter (Gao et al., 1999). The reduction in NMJ preterminal area in aging mice is prevented by sustained overexpression of IGF-1 and is consistent with the reported simplification of the postterminal (Pestronk et al., 1980).

To investigate the effects of aging and IGF-1 on the NMJ postsynaptic membrane, we measured the area defined by fluorescent $\alpha$-bungarotoxin staining as an indication of the acetylcholine receptor cluster area. Quantitative analysis showed a significant reduction of the postterminal $\alpha$-bungarotoxin surface with aging, probably resulting from the fragmentation and atrophy of sarcolemmal folds (see below). The decrease in the postterminal surface described here is congruent with a report on age-dependent decreases in acetylcholine receptor binding in EDL muscle (Banker et al., 1983).

The analysis of the motor endplate with electron microscopy showed a decrease in the number and length of postsynaptic folds as well as in the area and density of postsynaptic folds with aging. These results are in agreement with the analysis of the postterminal immunostained with $\alpha$-bungarotoxin and with previous studies done in aging mice using electron microscopy (Fahim and Robbins, 1982; Banker et al., 1983). Although aging endplates depict more dispersion of terminals into more synaptic regions than in the young-adult mouse, the dispersion seems to occur with no loss of junctional area or redistribution of terminal volume (Robbins and Fahim, 1985). Overexpression of IGF-1 in skeletal muscle prevents the described morphological changes with aging.

\section{Mechanisms of action of skeletal muscle IGF-1 overexpression on skeletal muscle innervation}

The mechanisms whereby overexpression of IGF-1 in skeletal muscle results in improvements in muscle innervation are not known. The survival of developing motor neurons depend on functional interaction with their target muscle (Greensmith and Vrbova, 1996). Although there is little evidence for an involvement in aging, a series of studies suggest a role for neurotrophins at least in the adult neuromuscular system (Lohof et al., 1993; Funakoshi et al., 1995; Boulanger and Poo, 1999; Schinder and Poo, 2000). Evidence supporting a role for neurotrophin signaling in age-related degeneration of the cutaneous innervation has come from observation of a close correlation between altered ligand-receptor expression(s) and axonal-terminal aberrations in senescence (Bergman et al., 2000).

A role for IGF-1 in therapeutics of motor neuron lesions and muscle innervation has been reported. IGF-1 enhances reinnervation of paralyzed ocular muscles (Thanos et al., 2001) and exerts long-term neuroprotective effects on motor neuron degen- eration (Di Giulio et al., 2000). Also, the downregulation of growth-associated proteins in motor neurons at the onset of synapse elimination is controlled by muscle activity and IGF-1 (Caroni and Becker, 1992). The same group has reported an increase in nerve sprouting in partially denervated or paralyzed adult mice and rats injected with IGF-1 in the target muscle (Caroni and Grandes, 1990). The neurite outgrowth response seems to be associated with binding of IGF-1 to its receptor at the nerve terminal, but no retrograde transport of ${ }^{125}$ I-IGF-2 by motor neuron processes in situ has been detected (Caroni and Grandes, 1990). It has been proposed that neurotrophic factors stimulate the intracellular release of the $\alpha$ subunit of $\mathrm{G}_{\mathrm{i}}$, which then acts as a stable retrograde signal transported via the axon to the perykaryon to act in the nucleus (Hendry and Crouch, 1991). The activation of $\mathrm{G}_{\mathrm{i} \alpha}$ would be related to cytoskeleton organization in response to growth factor stimulation (Crouch and Hendry, 1993; Johanson et al., 1995) through the activation of the gene expression of molecules such as GAP43 (Caroni, 1993). Although a series of studies support this possibility, there is no experimental evidence for a specific mechanism underlying the targetderived trophic effect on skeletal muscle innervation.

\section{References}

Bakker AJ, Head SI, Stephenson DG (1997) Time course of calcium transients derived from Fura-2 fluorescence measurements in single fast twitch fibres of adult mice and rat myotubes developing in primary culture. Cell Calcium 21:359-364.

Banker BQ, Kelly SS, Robbins N (1983) Neuromuscular transmission and correlative morphology in young and old mice. J Physiol (Lond) 339:355-377.

Barton-Davis ER, Shoturma DI, Musaro A, Rosenthal N, Sweeney HL (1998) Viral mediated expression of insulin-like growth factor I blocks the agingrelated loss of skeletal muscle function. Proc Natl Acad Sci USA 95:15603-15607.

Bergman E, Ulfhake B, Fundin BT (2000) Regulation of NGF-family ligands and receptors in adulthood and senescence: correlation to degenerative and regenerative changes in cutaneous innervation. Eur J Neurosci 12:2694-2706.

Bezakova G, Lomo T (2001) Muscle activity and muscle agrin regulate the organization of cytoskeletal proteins and attached acetylcholine receptor (AchR) aggregates in skeletal muscle fibers. J Cell Biol 153:1453-1463.

Boulanger L, Poo MM (1999) Presynaptic depolarization facilitates neurotrophin-induced synaptic potentiation. Nat Neurosci 2:346-351.

Buller AJ, Eccles JC, Eccles RM (1960a) Differentiation of fast and slow muscles in the cat hind limb. J Physiol (Lond) 150:399-416.

Buller AJ, Eccles JC, Eccles RM (1960b) Interactions between motoneurones and muscles in respect of the characteristic speeds of their responses. J Physiol (Lond) 150:417-439.

Caroni P (1993) Activity-sensitive signaling by muscle-derived insulin-like growth factors in the developing and regenerating neuromuscular system. Ann NY Acad Sci 692:209-222.

Caroni P, Becker M (1992) The downregulation of growth-associated proteins in motoneurons at the onset of synapse elimination is controlled by muscle activity and IGF1. J Neurosci 12:3849-3861.

Caroni P, Grandes P (1990) Nerve sprouting in innervated adult skeletal muscle induced by exposure to elevated levels of insulin like growth factors. J Cell Biol 110:1307-1317.

Coleman ME, DeMayo F, Yin KC, Lee HM, Geske R, Montgomery C, Schwartz RJ (1995) Myogenic vector expression of insulin-like growth factor I stimulates muscle cell differentiation and myofiber hypertrophy in transgenic mice. J Biol Chem 270:12109-12116.

Cowen T, Gavazzi I (1998) Plasticity in adult and aging sympathetic neurons. Prog Neurobiol 54:249-288.

Crouch MF, Hendry IA (1993) Growth factor second messenger systems: oncogenes and the heterotrimeric GTP-binding protein connection. Med Res Rev 13:105-123.

Damiani E, Larsson L, Margareth A (1996) Age-related abnormalities in regulation of the ryanodine receptor in rat fast-twitch muscle. Cell Calcium 19:15-27. 
Davies AM (1996) The neurotrophic hypothesis: where does it stand? Philos Trans R Soc Lond B Biol Sci 351:389-394.

Delaughter MC, Taffet GE, Fiorotto ML, Entman ML, Schwartz RJ (1999) Local insulin-like growth factor I expression induces physiologic, then pathologic, cardiac hypertrophy in transgenic mice. FASEB J 13:1923-1929.

Delbono O (1992) Calcium current activation and charge movement in denervated mammalian skeletal muscle fibres. J Physiol (Lond) 451:187-203.

Delbono O (2000) Regulation of excitation-contration coupling by insulinlike growth factor-1 in aging skeletal muscle. J Nutr Health Aging 4:162-164.

Delbono O (2003) Neural control of aging skeletal muscle. Aging Cell, in press.

Delbono O, Chu A (1995) $\mathrm{Ca}^{2+}$ release channels in rat denervated skeletal muscles. Exp Physiol 80:561-574.

Delbono O, Stefani E (1993) Calcium current inactivation in denervated rat skeletal muscle fibres. J Physiol (Lond) 460:173-183.

Delbono O, Renganathan M, Messi ML (1997) Excitation-Ca ${ }^{2+}$ releasecontraction coupling in single aged human skeletal muscle fiber. Muscle Nerve Suppl 5:S88-S92.

Di Giulio AM, Germani E, Lesma E, Muller E, Gorio A (2000) Glycosaminoglycans co-administration enhance insulin-like growth factor-I neuroprotective and neuroregenerative activity in traumatic and genetic models of motor neuron disease: a review. Int J Dev Neurosci 18:339-346.

Doherty TJ, Vandervoort AA, Taylor AW, Brown WF (1993) Effects of motor unit losses on strength in older men and women. J Appl Physiol 74:868-874.

Ecob-Prince M, Hill M, Brown W (1989) Immunocytochemical demonstration of myosin heavy chain expression in human muscle. J Neurol Sci 91:71-78.

Einsiedel LJ, Luff AR (1992) Effect of partial denervation on motor units in the ageing rat medial gastrocnemius. J Neurol Sci 112:178-184.

Fahim MA, Robbins N (1982) Ultrastructural studies of young and old mouse neuromuscular junctions. J Neurocytol 11:641-656.

Frey D, Schneider C, Xu L, Borg J, Spooren W, Caroni P (2000) Early and selective loss of neuromuscular synapse subtypes with low sprouting competence in motoneuron diseases. J Neurosci 20:2534-2542.

Funakoshi H, Belluardo N, Arenas E, Yamamoto Y, Casabona A, Persson H, Ibanez CF (1995) Muscle-derived neurotrophin-4 as an activity-dependent trophic signal for adult motor neurons. Science 268:1495-1499.

Gao WQ, Shinsky N, Ingle G, Beck K, Elias KA, Powell-Braxton L (1999) IGF-I deficient mice show reduced peripheral nerve conduction velocities and decreased axonal diameters and respond to exogenous IGF-I treatment. J Neurobiol 39:142-152.

Giulian GG, Moss RL, Greaser M (1983) Improved methodology for analysis and quantitation of proteins on one dimensional silver-stained slab gels. Anal Biochem 129:277-287.

González E, Messi ML, Delbono O (2000) Contractile properties of single intact mouse extensor digitorum longus (EDL), flexor digitorum brevis (FDB) and soleus muscle fibers. J Membr Biol 178:175-183.

Greensmith L, Vrbova G (1996) Motoneurone survival: a functional approach. Trends Neurosci 19:450-455.

Hammarberg H, Risling M, Hokfelt T, Cullheim S, Piehl F (1998) Expression of insulin-like growth factors and corresponding binding proteins (IGFBP 1-6) in rat spinal cord and peripheral nerve after axonal injuries. J Comp Neurol 400:57-72.

Hashizume K, Kanda K, Burke R (1988) Medial gastrocnemius motor nucleus in the rat: Age-related changes in the number and size of motoneurons. J Comp Neurol 269:425-430.

Hendry IA, Crouch MF (1991) Retrograde axonal transport of the GTPbinding protein $\mathrm{Gi}$ alpha: a potential neurotrophic intra-axonal messenger. Neurosci Lett 133:29-32.

Hughes SM, Cho M, Karsch-Mizrachi I, Travis M, Silberstein L, Leinwand LA, Blau HM (1993) Three slow myosin heavy chains sequentially expressed in developing mammalian skeletal muscle. Dev Biol 158:183-199.

Jerome WG, Minor LK, Glick JM, Rothblat GH, Lewis JC (1991) Lysosomal lipid accumulation in vascular smooth muscle cells. Exp Mol Pathol 54:144-158.

Johanson SO, Crouch MF, Hendry IA (1995) Retrograde axonal transport of signal transduction proteins in rat sciatic nerve. Brain Res 690:55-63.

Johnson H, Mossberg K, Arvidsson U, Piehl F, Hokfelt T, Ulfhake B (1995) Increase in alpha-CGRP and GAP-43 in aged motoneurons: a study of peptides, growth factors, and ChAT mRNA in the lumbar spinal cord of senescent rats with symptoms of hindlimb incapacities. J Comp Neurol 359:69-89.

Kadhiresan VA, Hassett CA, Faulkner JA (1996) Properties of single motor units in medial gastrocnemius muscles of adult and old rats. J Physiol (Lond) 493:543-552.

Kanda K, Hashizume K (1989) Changes in properties of the medial gastrocnemius motor units in aging rats. J Neurophysiol 1989:737-746.

Kanda K, Hashizume K (1992) Factors causing difference in force output among motor units in the rat medial gastrocnemius muscle. J Physiol (Lond) 448:677-695.

Karnovsky MJ, Roots I (1964) A direct colouring thiocholine method for cholinesterase. Cytochemistry 12:219.

Kimpinski K, Mearow K (2001) Neurite growth promotion by nerve growth factor and insulin-like growth factor-1 in cultured adult sensory neurons: role of phosphoinositide 3-kinase and mitogen activated protein kinase. J Neurosci Res 63:486-499.

Larsson L (1995) Motor units: remodeling in aged animals. J Gerontol A Biol Sci Med Sci 50:91-95.

Lexell J (1995) Human aging, muscle mass, and fiber type composition. J Gerontol A Biol Sci Med Sci 50:11-16.

Lohof AM, Ip NY, Poo MM (1993) Potentiation of developing neuromuscular synapses by the neurotrophins NT-3 and BDNF. Nature 363:350-353.

Musaro A, McCullagh KJ, Paul A, Houghton L, Dobrowolny G, Molinaro M, Barton-Davis ER, Sweeney HL, Rosenthal N (2001) Localized IGF-1 transgene expression sustains hypertrophy and regeneration in senescent skeletal muscle. Nat Genet 27:195-200.

Neff NT, Prevette DM, Houenou LJ, Lewis ME, Glicksman MA, Yin Q-W, Oppenheim RW (1993) Insulin-like growth factors: Putative musclederived trophic agents that promote motoneuron survival. J Neurobiol 24:1578-1588.

O'Kusky JR, Ye P, D'Ercole J (2000) Insulin-Like growth factor-1 promotes neurogenesis and synaptogenesis in the hippocampal dentate gyrus during postnatal development. J Neurosci 15:8435-8442.

Owino W, Yang SY, Goldspink G (2001) Age-related loss of skeletal muscle function and the inability to express the autocrine form of insulin-like growth factor-1 (MGF) in response to mechanical overload. FEBS Lett 505:259-263.

Pestronk A, Drachman DB (1978) A new stain for quantitative measurement of sprouting at neuromuscular junctions. Muscle Nerve 1:70-74.

Pestronk A, Drachman DB, Griffin JW (1980) Effects of aging on nerve sprouting and regeneration. Exp Neurol 70:65-82.

Pette D, Staron RS (2001) Transitions of muscle fiber phenotypic profiles. Histochem Cell Biol 115:359-372.

Renganathan M, Sonntag WE, Delbono O (1997a) L-type Ca ${ }^{2+}$ channelinsulin-like growth factor-1 receptor signaling impairment in aging rat skeletal muscle. Biochem Biophys Res Commun 235:784-789.

Renganathan M, Messi ML, Schwartz R, Delbono O (1997b) Overexpression of hIGF-1 exclusively in skeletal muscle increases the number of dihydropyridine receptors in adult transgenic mice. FEBS Lett 417:13-16.

Renganathan M, Messi ML, Delbono O (1998) Overexpression of IGF-1 exclusively in skeletal muscle prevents age-related decline in the number of dihydropyridine receptors. J Biol Chem 273:28845-28851.

Rind HB, von Bartheld CS (2002) Target-derived cardiotrophin-1 and insulin-like growth factor-I promote neurite growth and survival of developing oculomotor neurons. Mol Cell Neurosci 19:58-71.

Robbins N (1992) Compensatory plasticity of aging at the neuromuscular junction. Exp Gerontol 27:75-81.

Robbins N, Fahim MA (1985) Progression of age changes in mature mouse motor nerve terminals and its relation to locomotor activity. J Neurocytol 14:1019-1036.

Robbins N, Nakashiro S (1993) Connections among plasticity, regeneration, and aging at the neuromuscular junction. Adv Neurol 59:47-52.

Salvatori S, Damiani E, Zorzato F, Volpe P, Pierobon S, Quaglino D, Salviati G, Margreth A (1988) Denervation-induced proliferative changes of triads in rabbit skeletal muscle. Muscle Nerve 11:1246-1259.

Schiaffino S, Reggiani C (1994) Myosin isoforms in mammalian skeletal muscle. J Appl Physiol 77:493-501.

Schinder AF, Poo M (2000) The neurotrophin hypothesis for synaptic plasticity. Trends Neurosci 23:639-645.

Serrano AL, Petrie JL, Rivero JLL, Hermanson JW (1996) Myosin isoforms 
and muscle fiber characteristics in equine gluteus medius muscle. Anat Rec 244:444-451.

Streppel M, Azzolin N, Dohm S, Guntinas-Lichius O, Haas C, Grothe C, Wevers A, Neiss WF, Angelov DN (2002) Focal application of neutralizing antibodies to soluble neurotrophic factors reduces collateral axonal branching after peripheral nerve lesion. Eur J Neurosci 15:1327-1342.

Thanos PK, Tiangco DA, Terzis JK (2001) Enhanced reinnervation of the paralyzed orbicularis oculi muscle after insulin-like growth factor-I (IGF-I) delivery to a nerve graft. J Reconstr Microsurg 17:357-362.

Urbancheck MG, Picken EB, Kalliainen LK, Kuzon WM (2001) Specific force deficit in skeletal muscles of old rats is partially explained by the existence of denervated muscle fibers. J Gerontol A Biol Sci Med Sci 56:B191-B198.

Vergani L, Di Giulio AM, Losa M, Rossoni G, Muller EE, Gorio A (1998) Systemic administration of insulin-like growth factor decreases motor neuron cell death and promotes muscle reinnervation. J Neurosci Res $54: 840-847$.
Wang Z-M, Messi ML, Delbono O (2000) L-type $\mathrm{Ca}^{2+}$ channel charge movement and intracellular $\mathrm{Ca}^{2+}$ in skeletal muscle fibers from aging mice. Biophys J 78:1947-1954.

Ye P, Xing Y, Dai Z, D'Ercole J (1996) In vivo actions of insulin-like growth factor-I (IGF-1) on cerebellum development in transgenic mice: evidence that IGF-1 increases proliferation of granule cells progenitors. Dev Brain Res 95:44-54.

Zhang C, Goto N, Suzuki M, Ke M (1996) Age-related reductions in number and size of anterior horn cells at C6 level of the human spinal cord. Okajimas Folia Anat Jpn 73:171-177.

Zheng Z, Messi ML, Delbono O (2001a) Age-dependent IGF-1 regulation of gene transcription of $\mathrm{Ca}^{2+}$ channels in skeletal muscle. Mech Ageing Dev 122:373-384.

Zheng Z, Wang Z-M, Delbono O (2001b) IGF-1 increases transcriptional activity of the skeletal muscle DHPR alpha-1 subunit by acting on CREB element of the promoter region. Soc Neurosci Abstr 27:519.511. 